\section{Invigorating IVIG}

\section{By Stephen Parmley, Senior Writer}

Although IVIG has been a mainstay in autoimmune disease therapy for decades, there is still high variability in both safety and potency among different batches because the antibodies are sourced from pooled human blood. arGEN-X N.V. has developed a mutant constant region fragment of IgG1 that binds its receptor with higher affinity than IgG and has now shown that it can clear unwanted serum antibodies in nonhuman primates about 30 times more efficiently than standard IVIG.

arGEN-X's compound-ARGX-113joins a wave of preclinical programs using recombinant approaches in a field that has seen little innovation until recently.

Since the demonstration of the broad therapeutic potential of IVIG (intravenous immunoglobulin) a few decades ago, there has been a dearth of therapies that improve upon it. Although there are at least six IVIG therapies on the market and at least three subcutaneous Ig (SCIG) compounds approved or on the market, there are no disclosed programs in the clinic for new forms of IVIG. By contrast, since 2011, at least 3 preclinical programs have been announced in addition to ARGX-113 (see Table 1, "Ig therapies").

IVIG was originally used as replacement therapy in primary immune deficiencies of genetic origin, but in recent years its on- and off-label use has extended to a broad range of immune disorders.

Marketed IVIG and SCIG compounds are isolated from pooled plasma from tens of thousands of donors, but only a small fraction of the pooled Ig is therapeutically active. As a consequence, high doses are needed for efficacy and treatment often requires four- to six-hour infusions. Despite the fact that the problems with IVIG's production and efficacy have been known for years, its mechanism of action is poorly understood, and thus researchers have struggled to create an improved product.

In the last decade, however, insights into the immunomodulatory role of the constant region ( $\mathrm{Fc}$ ) of IgG antibodies in IVIG have stimulated new thinking about how the therapy suppresses autoimmunity. Work in the early 2000s showed that the IVIG components with the greatest anti-inflammatory activity contained sialylated Fc regions. ${ }^{1}$ That led to a focus on Fc regions that form the basis of the recent preclinical programs.

"Innovation on improving on IVIG was kind of stuck," said Anthony Manning, VP of research at Momenta Pharmaceuticals Inc. "I think people found it really difficult to deconstruct what is in IVIG and how it is working. If you don't do that, you can't really understand how to make it better."

He added, "Jeff Ravetch identified sialic acid on the constant region of the IgG that has anti-inflammatory activities. I think that has been one of the big advances in the field."

Momenta has a sialylated IVIG obtained from its acquisition of the assets from Jeffrey Ravetch's startup, Virdante Pharmaceuticals Inc. Ravetch is a professor at The Rockefeller University. He declined a request to comment.

Although there is no consensus yet about IVIG's mechanism of action, two hypotheses dominate and both suggest the Fc regions in IVIG antibodies compete with Fc domains of pathogenic antibodies. One hypothesis is that the IVIG Fc domains prevent the Fc domains of pathogenic antibodies from stimulating immune cell activation or inhibiting immune cell suppression. The other hypothesis is that IVIG Fc regions compete with pathogenic antibodies for binding to Fc fragment of IgG receptor transporter- $\alpha$ (FCGRT; FCRN). FCRN mediates the recycling of antibodies and thus prolongs their serum circulation time. Pathogenic antibodies blocked from binding the receptor cannot enter the recycling route after internalization into cells and instead undergo intracellular degradation.

arGEN-X's strategy is based on the FCRN hypothesis, and its compound is designed to saturate FCRN receptors with greater efficiency than IVIG-which is limited by the low affinity of natural IgG for FCRN. The goal is to develop a treatment that avoids the batch variability of blood-sourced IVIG, acts faster and with greater potency than IVIG and can be used in autoimmune diseases caused by elevated levels of serum autoantibodies.

\section{The ABDEG of IVIG}

Using the company's antibody engineering ABDEG technology, arGEN-X engineered ARGX-113 by introducing five mutations into the $\mathrm{CH} 2$ and $\mathrm{CH} 3$ constant domains of the Fc fragment of human IgG1 to enhance the fragment's affinity for FCRN. According to arGEN-X, ARGX-113 retains its high affinity for FCRN at both $\mathrm{pH} 7.4$ and $\mathrm{pH} 6$ and thus remains bound to the receptor as it cycles from the $\mathrm{pH}$-neutral cell surface to the acidic endocytic compartment.

Previously, arGEN-X demonstrated that a precursor to ARGX-113 reduced pathogenic autoantibody levels in serum and CNS in mouse models of arthritis and experimental autoimmune encephalomyelitis, respectively, thereby improving symptoms in each model.

Now, the company has presented data from nonhuman primates showing that a single dose of ARGX-113 cleared a tracer IgG faster and more extensively than a 30-fold higher dose of IVIG. In cynomolgus monkeys, about $40 \%$ of the tracer remained in serum 5 days after treatment with $2 \mathrm{~g} / \mathrm{kg}$ standard IVIG, whereas less than $5 \%$ of the tracer remained 3 days after treatment with $70 \mathrm{mg} / \mathrm{kg}$ ARGX-113. 
Table 1. Ig therapies. At least nine blood-derived lg products are marketed or approved and at least four next-generation products are in development.

Source: $B C I Q$ : BioCentury Online Intelligence

\begin{tabular}{|c|c|c|c|c|c|}
\hline Product type & Product name & Description & $\begin{array}{l}\text { Company name } \\
\text { (originator) }\end{array}$ & Indications & Status \\
\hline \multirow{6}{*}{ IVIG therapies } & $\begin{array}{l}\text { Gammagard liquid } \\
10 \%\end{array}$ & $10 \%$ formulation of IVIG & $\begin{array}{l}\text { Baxter International Inc. } \\
\text { (NYSE:BAX) }\end{array}$ & $\begin{array}{l}\text { Immunodeficiency; multifocal motor } \\
\text { neuropathy; idiopathic thrombocytopenic } \\
\text { purpura (ITP); Guillain-Barré syndrome; } \\
\text { Kawasaki disease }\end{array}$ & Marketed \\
\hline & Gammaplex & $5 \%$ formulation of IVIG & Bio Products Laboratory Ltd. & Immunodeficiency; ITP & Marketed \\
\hline & Bivigam & $10 \%$ formulation of IVIG & Biotest AG (Xetra:BIO) & Immunodeficiency & Marketed \\
\hline & Privigen & $10 \%$ formulation of IVIG & CSL Ltd. (ASX:CSL) & $\begin{array}{l}\text { Immunodeficiency; ITP; chronic } \\
\text { inflammatory demyelinating } \\
\text { polyneuropathy (CIDP) }\end{array}$ & Marketed \\
\hline & $\begin{array}{l}\text { Gamunex-C } \\
\text { (immune globulin) }\end{array}$ & $10 \%$ formulation of IVIG & $\begin{array}{l}\text { Grifols S.A. (Madrid:GRF; } \\
\text { NASDAQ:GRFS) }\end{array}$ & Immunodeficiency; ITP; CIDP & Marketed \\
\hline & Octagam & $5 \%$ and $10 \%$ high-purity IVIG & Octapharma AG & Immunodeficiency; ITP & Marketed \\
\hline \multirow{3}{*}{$\begin{array}{l}\text { Subcutaneous } \\
\text { Ig (SCIG) } \\
\text { therapies }\end{array}$} & HyQvia & $10 \%$ formulation of SCIG & Baxter International & Immunodeficiency & Approved \\
\hline & Hizentra & $20 \%$ formulation of SCIG & CSL & Immunodeficiency & Marketed (Japan) \\
\hline & Gammanorm & $16.5 \%$ formulation of SCIG & Octapharma & Immunodeficiency & Marketed \\
\hline \multirow{4}{*}{$\begin{array}{l}\text { Next- } \\
\text { generation } \\
\text { therapies }\end{array}$} & ARGX-113 & $\begin{array}{l}\text { Recombinant human IgG } \\
\text { Fc domain created using } \\
\text { ABDEG technology }\end{array}$ & $\begin{array}{l}\text { arGEN-x N.V. } \\
\text { (Euronext: ARGX) }\end{array}$ & Autoimmune disease & Preclinical \\
\hline & GL-2045 & $\begin{array}{l}\text { Recombinant stradomer- } \\
\text { laboratory-made clusters } \\
\text { of the Fc portion of human } \\
\text { antibodies-designed to } \\
\text { mimic IVIG }\end{array}$ & $\begin{array}{l}\text { Gliknik Inc.; Pfizer Inc. } \\
\text { (NYSE:PFE) }\end{array}$ & $\begin{array}{l}\text { Myasthenia gravis; rheumatoid arthritis } \\
\text { (RA) }\end{array}$ & Preclinical \\
\hline & sIVIG & $\begin{array}{l}\text { Sialylated version of IVIG } \\
\text { (sIVIG) }\end{array}$ & $\begin{array}{l}\text { Momenta Pharmaceuticals } \\
\text { Inc. (NASDAQ:MNTA) }\end{array}$ & Inflammation & Preclinical \\
\hline & rIVIG & Recombinant IVIG (rIVIG) & $\begin{array}{l}\text { Sorrento Therapeutics Inc. } \\
\text { (NASDAQ:SRNE) }\end{array}$ & Inflammation & Preclinical \\
\hline
\end{tabular}

However, a single dose of ARGX-113 also reduced levels of endogenous IgG by up to $55 \%$ for at least 15 days after infusion. That suggests repeat dosing might lead to low levels of IgGhypogammaglobulinemia-which could put patients at risk for opportunistic infections as has been observed with anti-CD20 antibody treatment. $^{2}$

However, Torsten Dreier, chief development officer at arGEN-X, told SciBX that although the total IgG reduction might create a safety risk, additional preclinical studies showed that other Ig subtypes were not affected by ARGX-113.

"The medical literature indicates that transient depletion of IgGs should be well tolerated," he said. "Unlike therapies which result in prolonged hypogammaglobulinemia following B cell depletion approaches, transient reduction in circulating IgG levels is not associated with an increased risk of infection."

Results were presented at the 2014 Protein and Antibody Engineering Summit in May.

According to Dreier, the compound could be particularly useful in an autoimmune setting in which management of acute flares is needed. He added that because ARGX-113 has a faster onset of action and is more effective at IgG clearance than IVIG, it could reduce the need for hospitalization in severe autoimmune crises. The company's initial focus will be in the acute setting, but Dreier said that there is obvious potential for the prevention of flares.
arGEN-X plans to begin Phase I studies of ARGX-113 in 2H15. It intends to perform subsequent studies in a number of orphan diseases that include myasthenia gravis and blistering skin diseases such as pemphigus vulgaris. Dreier said that the company would seek to partner the program for major autoimmune diseases after showing proof of concept in one or more orphan indications.

\section{IVIG innovation}

Other preclinical compounds aimed at replacing IVIG include Gliknik Inc.'s recombinant multimeric Fc, Momenta's sialylated version of IVIG and Sorrento Therapeutics Inc.'s recombinant IVIG.

Gliknik's approach is to develop a compound that targets multiple Fc-mediated mechanisms of anti-inflammatory activity. "One possible barrier to new, innovative alternatives to pooled human IVIG may be the industry's general preference for developing drugs that work through a single mechanism of action," President and CEO David Block told SciBX. "Pooled human IVIG works through numerous mechanisms, and the mechanisms that are most important are likely different in different clinical indications."

Gliknik has developed its lead compound, GL-2045, using its stradomer multimerization technology and designed the compound to mimic the naturally occurring aggregates in IVIG that are thought to potentiate Fc-mediated mechanisms.

According to Block, the idea is that the multimer's polyvalent Fc should act like the aggregates and compete with pathogenic immune complexes 


\section{ANALYSIS}

for binding to complement component $1 \mathrm{q}$ subcomponent $(\mathrm{C} 1 \mathrm{q})$ and $\mathrm{Fc}$ receptors. $\mathrm{C} 1 \mathrm{q}$ is a key trigger of the complement cascade that can lead to tissue damage in autoimmune diseases.

However, according to Falk Nimmerjahn, recombinant compounds that simultaneously target multiple Fc-mediated mechanisms might have to walk a fine line between blocking inflammatory signals and triggering immune activation. Those compounds would need to be carefully titrated, he said.

Nimmerjahn is a professor of genetics at the University of ErlangenNuremberg and coauthored the early IVIG sialylation study with Ravetch. He recently collaborated with Momenta on mouse studies of skin blistering disease using its sialylated IVIG preparations.

Gliknik has partnered with Pfizer Inc. and plans to test GL-2045 in myasthenia gravis and rheumatoid arthritis. Block told SciBX that Pfizer expects to advance GL-2045 rapidly through early phase clinical studies but declined to give a timeline.

Momenta's sialylated IVIG aims to capitalize on the high antiinflammatory activity of that fraction of total IVIG. Earlier this year, the company reported that their enzymatically sialylated blood-derived IVIG produced greater anti-inflammatory effects than equivalent doses of standard, unmodified IVIG in several mouse models of autoimmune disease. The company has now produced a sialylated recombinant Fc molecule and used it to replicate the animal data obtained with the enzymatically sialylated IVIG, Manning told SciBX.
Momenta has not disclosed its development plans for the program.

Sorrento's recombinant IVIG is a pool of recombinant human antibodies that include anti-inflammatory IgGs, Fc domains and antipathogen antibodies. Gunnar Kaufmann, senior director of R\&D at Sorrento, told SciBX that the technology is designed to mimic donor-derived IVIG, solve bottlenecks of supply shortage and increase batch consistency. The company has not disclosed its development plans.

With additional reporting from Lauren Martz, Staff Writer.

Parmley, S. SciBX 7(39); doi:10.1038/scibx.2014.1138 Published online Oct. 9, 2014

\section{REFERENCES}

1. Kaneko, Y. et al. Science 313, 670-673 (2006)

2. Makatsori, M. et al. QJM 107, 821-828 (2014)

\section{COMPANIES AND INSTITUTIONS MENTIONED}

arGEN-X N.V. (Euronext: ARGX), Breda, the Netherlands

Gliknik Inc., Baltimore, Md.

Momenta Pharmaceuticals Inc. (NASDAQ:MNTA), Cambridge, Mass. Pfizer Inc. (NYSE:PFE), New York, N.Y.

The Rockefeller University, New York, N.Y.

Sorrento Therapeutics Inc. (NASDAQ:SRNE), San Diego, Calif. University of Erlangen-Nuremberg, Erlangen, Germany 